\title{
EFEKTIVITAS PENYULUHAN DALAM PENERAPAN TEKNOLOGI DETEKSI BIRAHI SEBAGAI UPAYA MENINGKATKAN KEBERHASILAN INSEMINASI BUATAN PADA SAPI POTONG
}

\section{THE EFFECTIVITIES OF COUNSELING IN THE APPLICATION OF ESTROUS DETECTION TECHNOLOGY AS AN EFFORT TO INCREASE THE SUCCESS OF ARTIFICIAL INSEMINATION IN BEEF CATTLE}

\author{
LILI ADAM YULIANDRI*, ULFA INDAH LAELA RAHMAH, DULHAMID \\ Program Studi Peternakan, Fakultas Pertanian Universitas Majalengka \\ Alamat : Jl. KH. Abdul Halim No. 103 Kabupaten Majalengka, 45418 \\ *Email : liliadamyuliandri1984@gmail.com
}

\begin{abstract}
This research was carried out in Gemah Ripah IV Group, Japara Village, Japara District, Kuningan Regency from March 8 to May 25, 2021. The research aims to analyze the characteristics of breeders that affect the effectiveness of extension, and analyze the effectiveness of extension in the application of estrous detection technology as an effort to improve the artificial insemination success in beef cattle. The method in this study is a survey method, and the data obtained by census is a data collection technique by including all members of the population as research samples. The results showed that the characteristics of the breeders were included in the fairly good category, the average respondents were of productive age and formal education. Knowledge about cattle reproduction increased $(P<0.05)$ was influenced by education and length of rearing, while the attitude of farmers in response to the results of counseling increased $(P<0.05)$ only affected by length of rearing. So it can be concluded that in general the knowledge and attitudes of farmers towards the application of estrous technology are dominantly influenced by education factors and length of raising, and counseling is considered quite effective to increase the application of the technology.
\end{abstract}

Keywords: Characteristics of farmers, effectiveness of counseling

\begin{abstract}
ABSTRAK
Penelitian ini dilaksanakan di Kelompok Gemah Ripah IV, Desa Japara, Kecamatan Japara, Kabupaten Kuningan dari tanggal 8 Maret sampai dengan tangga 25 Mei 2021. Penelitian bertujuan untuk menganalisis faktor-faktor karakteristik peternak yang mempengaruhi efektivitas penyuluhan, dan menganalisis efektivitas penyuluhan dalam penerapan teknologi deteksi birahi sebagai upaya meningkatkan keberhasilan IB pada sapi potong. Metode dalam penelitian ini adalah metode survei, yaitu teknik pengambilan data dengan mengikutsertakan semua anggota populasi sebagai sampel penelitian. Hasil penelitian menunjukan bahwa karakteristik peternak termasuk dalam kategori cukup baik, rata-rata responden berusia produktif dan berpendidikan formal. Pengetahuan tentang reproduksi sapi meningkat $(\mathrm{P}<0,05)$ dipengaruhi oleh pendidikan dan lama beternak, sementara sikap peternak tanggap terhadap hasil penyuluhan meningkat $(\mathrm{P}<0,05)$ hanya dipengaruhi oleh lamanya beternak. Maka dapat disimpulkan bahwa secara umum pengetahuan dan sikap peternak terhadap aplikasi teknologi birahi dominan dipengaruhi oleh faktor pendidikan dan lama beternak, dan penyuluhan dinilai cukup efektif untuk meningkatkan penerapan teknologi tersebut.
\end{abstract}

Kata kunci: Karakteristik peternak, efektivitas penyuluhan.

\section{PENDAHULUAN}

Desa Japara Kecamatan Japara merupakan salah satu desa yang memiliki usaha peternakan sapi potong di Kabupaten Kuningan. Mayoritas usaha peternakan dikelola dengan pola produksi induk-anak (cow-calf operation) dengan sistem pembibitan dan pembesaran dalam skala usaha kecil yang dikelola sendiri oleh rumah tangga petani, dengan modal, tenaga kerja, dan manajemen yang terbatas.
Berdasarkan data Badan Pusat Statistik Prov. Jabar tahun 2016 , dalam kurun waktu 5 tahun terakhir, populasi ternak sapi potong di Kabupaten Kuningan menurun populasinya. Persentase kelahiran (perbandingan antara jumlah induk dengan anak yang dilahirkan) masih rendah yaitu $<60 \%$, pada kisaran $26-55 \%$. Rendahnya produktivitas ternak dan kualitas mutu genetik ternak disebabkan karena pada umumnya peternak masih mengandalkan pola 
tradisional dalam pengembangan ternaknya dan masih belum menerapkan teknologi budidaya sapi potong dengan baik sehingga mempengaruhi produksi dan kualitas mutu genetik pada ternak itu sendiri.

Menurut Kepala Dinas Pertanian Ir. $\mathrm{Hj}$. Triastami melalui Kasi Produksi Peternakan Suhyana, SP., teknologi Inseminasi Buatan (IB) sudah lama dikenal dan diterapkan oleh peternak di Desa Japara sebagai terobosan dalam pengembangan populasi ternak. Keberhasilan IB sangat dipengaruhi oleh akurasi deteksi birahi, keterampilan inseminator, dan ketepatan waktu pelaksanaan IB.

Salah satu penyebab gagalnya pelaksanaan IB di Kabupaten Kuningan adalah tidak streilnya ketika proses pembuahaan serta ketidak akuratan dalam mendeteksi birahi, sehingga harus melakukan kawin yang berulang akibat rendahnya persentase kebuntingan yang berdampak terhadap panjangnya jangka waktu beranak (calving interval) (Kuningan mass, 2017).

Solusi untuk mengatasi permasalahan tersebut yaitu dengan memberikan penyuluhan kepada peternak tentang teknologi deteksi birahi. Tujuan dari penyuluhan adalah meningkatkan pengetahuan, sikap dan keterampilan dalam penerapan teknologi deteksi birahi sehingga keberhasilan kegiatan IB bisa meningkat. Penyuluhan bisa dikatakan efektif jika mampu memberikan pengaruh dan perubahan ke arah yang lebih baik. Efektivitas penyuluhan peternakan banyak dipengaruhi oleh karakteristik peternak, antara lain umur peternak, pendidikan peternak, jumlah ternak dan lama beternak.

\section{METODE PENELITIAN}

Metode yang digunakan dalam penelitian ini adalah metode survey (Adiyanta, 2019). Data diperoleh secara sensus yaitu teknik pengambilan data dengan mengikutsertakan semua anggota populasi sebagai sampel penelitian.

Penentuan daerah penelitian dilakukan secara sengaja (purposive) berdasarkan pertimbangan bahwa terdapat populasi ternak sapi potong terbanyak di Kecamatan Japara. Peternak sapi di Desa Japara adalah binaan Petugas Penyuluh Lapangan (PPL), sehingga penelitian tentang faktor-faktor yang mempengaruhi persepsi efektivitas penyuluhan pertanian layak dilakukan.
Responden dalam penelitian adalah peternak sapi potong Kelompok Gemah Ripah IV Desa Japara Kecamatan Japara Kabupaten Kuningan sebanyak 30 orang. Jenis data yang digunakan dalam penelitian bersumber dari data primer dan sumber data sekunder. Data primer diperoleh melalui: 1) Wawancara langsung kepada peternak untuk memperoleh gambaran karakterisitik peternak yang meliputi nama, umur peternak, pendidikan peternak, lama beternak dan jumlah ternak; 2) pemberian kuesioner untuk mengukur pengetahuan dan sikap peternak terkait deteksi birahi sapi potong; dan 3) observasi langsung untuk melihat tindakan peternak dalam penerapan deteksi birahi pada sapi potong. Sedangkan data sekunder merupakan data pendukung kegiatan kajian yang diperoleh dari data penyuluh, monografi wilayah, dinas peternakan dan sumber lainnya yang terkait dengan kajian. Evaluasi kegiatan penyuluhan diukur berdasarkan hasil tes awal (Pre test) yang dilakukan sebelum penyuluhan dan tes akhir (Pos test) yang dilakukan sesudah penyuluhan. Efektivitas penyuluhan diukur berdasarkan peningkatan pengetahuan dan sikap peternak (responden) dengan menggunakan daftar pertanyaan (kuesioner) terdiri dari masing masing aspek sebanyak 10 pertanyaan dengan nilai tertinggi 4 (empat) dan nilai terendah 1 (satu). Dengan kriteria tingkat pengetahuan dan sikap yang diperoleh masing-masing responden dapat diinterprestasikan sebagai berikut :

- Nilai tertinggi (maksimal) $10 \times 4=40$

- Nilai terendah (minimum) $10 \times 1=10$

Kriteria tingkat pengetahuan dan sikap yang diperoleh masing-masing responden dikelompokkan dalam tiga kategori, yaitu; Baik $>31-40$, sedang $>21-30$, dan kurang 10-20.

Metode analisis data yang digunakan dalam penelitian ini menggunakan analisis kuantitatif deskriptif dengan menggunakan analisis tabulasi silang sederhana pada umur peternak, pendidikan peternak, lama beternak dan jumlah ternak terhadap perilaku petani (pengetahuan, sikap dan keterampilan) dalam penerapan teknologi deteksi birahi (Kurnia et al., 2019).

Hasil analisis data diinterpretasikan berdasarkan pedoman yang disampaikan oleh Sugiyono (2017) dalam Robiyanto et al. (2019) sebagai berikut:

$$
\begin{aligned}
& -0,00-0,199=\text { sangat rendah } \\
& -0,20-0,399=\text { rendah } \\
& -0,40-0,599=\text { sedang }
\end{aligned}
$$


$-0,60-0,799=$ kuat

$-0,80-1,000=$ sangat kuat.

Untuk menganalisis faktor-faktor yang mempengaruhi efektivitas penyuluhan digunakan analisis regresi linier berganda. dengan model persamaan regresi linier berganda dalam penelitian ini adalah sebagai berikut :

$Y=a+b 1 X_{1}+b 2 X_{2}+b 3 X_{3}+b 4 X_{4}$

Keterangan:

$\mathrm{Y}=$ Efektivitas penyuluhan

$\mathrm{a}=$ Konstanta

b1, b2, b3, b4 = Koefsien variabel bebas

$\mathrm{X}_{1}=$ Umur peternak

$\mathrm{X}_{2}=$ Pendidikan peternak

$\mathrm{X}_{3}=$ Lama beternak

$\mathrm{X}_{4}=$ Jumlah ternak

\section{HASIL DAN PEMBAHASAN}

\section{Karakteristik Responden}

Karakteristik adalah ciri-ciri atau sifatsifat yang dimiliki oleh seseorang yang ditampilkan melalui pola pikir, pola sikap dan pola tindakan terhadap lingkungannya (Suharja, 2014).

Sebagian besar responden berumur produktif $(90 \%)$ dengan kisaran umur 20-64 tahun (Tabel 1). Usia yang cukup produktif berpengaruh terhadap kemampuan fisik peternak untuk bekerja secara optimal. Penelitian ini sejalan dengan penelitian Yuliandri, $d k k$, (2020) yang menyatakan bahwa beternak merupakan salah satu mata pencaharian kedua setelah bertani, sehingga sebagian besar masyarakat (kelompok usia produktif) menggeluti usaha bertani.

Pandangan karakteristik responden yang mencakup usia, pendidikan, lama beternak dapat dilihat pada Tabel 1.

Tabel 1. Distribusi Karakteristik Responden

\begin{tabular}{lcc}
\hline $\begin{array}{c}\text { Karakteristik } \\
\text { responden }\end{array}$ & $\begin{array}{c}\text { Jumlah } \\
\text { responden } \\
\text { (orang) }\end{array}$ & $\begin{array}{c}\text { Persentase } \\
(\%)\end{array}$ \\
\hline $\begin{array}{l}\text { Umur peternak } \\
\text { (tahun): }\end{array}$ & & \\
$\quad 20-64$ & 27 & 90 \\
$\quad 64$ & 3 & 10 \\
Pendidikan peternak: & & \\
$\quad$ Formal & 19 & 63 \\
$\quad$ Formal dan & 11 & 37
\end{tabular}

\begin{tabular}{lcc}
$\begin{array}{l}\text { Non formal } \\
\text { Lama beternak } \\
\text { (Tahun): }\end{array}$ & \\
$1-10$ & 18 & 60 \\
$11-20$ & 7 & 23 \\
$>20$ & 5 & 17 \\
Jumlah ternak (ekor): & & \\
$1-2$ & 17 & 57 \\
$3-4$ & 9 & 30 \\
$\geq 5$ & 4 & 13 \\
\hline Sumber : Data primer diolah, 2021.
\end{tabular}

Responden yang mengikuti pendidikan formal dan non formal (Diklat, pelatihan, dll) lebih sedikit dibandingkan dengan responden yang hanya mengikuti pendidikan formal sebesar (37\%) sehingga dapat dikatakan sumberdaya manusia (SDM) peternak masih tergolong rendah, sebab pendidikan seseorang menentukan keberhasilan dalam mengelola usaha ternaknya.Peternak atau responden yang memiliki pola pikir yang baik, dia mampu mengadopsi pengembangan informasi dan inovasi teknologi khususnya teknologi di bidang peternakan dengan cepat. Meskipun dengan pendidikan yang rendah, sikap dan pandangan peternak tentang usaha tani ternaknya sudah mulai maju. Belajar dari pengalaman dan pengetahuan menyebabkan kemampuan peternak untuk mengambil keputusan semakin baik dan cermat. (Hifijah, dkk 2015).

Pengalaman beternak responden rata-rata 1-10 tahun (60\%), pengalaman beternak rata-rata peternak sapi di Kabupaten Majalengka sudah lama dalam beternak sapi dan merupakan usaha turun temurun dari keluarganya. Sejalan dengan pendapat Yuliandri, $d k k$, (2020) bahwa beternak merupakan salah satu mata pencaharian yang telah diwarisi masyarakat Indonesia yang umumnya dari para pendahulunya.

Skala kepemilikan ternak rata-rata 1-2 ekor (57 \%), hal ini memperlihatkan bahwa umumnya usaha ternak sapi di daerah penelitian masih tergolong peternakan rakyat. Yuliandri, $d k k$, (2020) menyatakan bahwa usaha peternakan rakyat bercirikan antara lain berskala usaha kecil atau usaha rumah tangga, produktivitas rendah, mutu produk kurang terjamin dan belum sepenuhnya berorientasi pasar.

\section{Kognitif (Pengetahuan)}

Pengaruh karakteristik responden terhadap peningkatan pengetahuan melalui penyuluhan dapat dilihat pada Tabel 2. 
Tabel 2. Peningkatan pengetahuan berdasarkan karakteristik responden

\begin{tabular}{lccc}
\hline Karakteristik Responden & Nilai Pre test & Nilai Postest & Selisih Nilai \\
\hline Umur peternak (tahun): & & & \\
$\quad$ 20-64 & 22,8 & 35,0 & 12,2 \\
$\quad$ > 64 & 27,0 & 38,0 & 11,0 \\
Pendidikan peternak: & & & \\
$\quad$ Formal & 23,3 & 32,6 & 9,3 \\
$\quad$ Formal dan Non formal & 23,1 & 40,0 & 16,9 \\
Lama Beternak (Tahun): & & & \\
1-10 & 23,0 & 32,5 & 9,5 \\
11-20 & 23,7 & 39,1 & 15,4 \\
$\quad$ 20 & 24,0 & 40,0 & 16,0 \\
Jumlah Ternak (ekor): & & & \\
1-2 & 19,0 & 31,0 & 12,0 \\
3-4 & 23,0 & 34,2 & 1,2 \\
$\geq 5$ & 23,2 & 40,0 & 16,8 \\
\hline
\end{tabular}

Sumber : Data primer diolah, 2021.

Berdasarkan Tabel 2, diketahui bahwa seluruh responden yang telah diberikan penyuluhan mendapatkan nilai pengetahuan dengan kategori baik. Responden berumur produktif lebih respon terhadap materi yang disampaikan dalam penyuluhan. Hal tersebut sesuai dengan penelitian Mulyawati et al. (2016), bahwa semakin muda umur peternak biasanya memiliki semangat dan keinginan untuk mengetahui inovasi terbaru meski pengalaman beternaknya kurang. Peternak yang berusia lanjut biasanya fanatik terhadap tradisi dan sulit untuk diberikan pengertian-pengertian yang dapat mengubah cara berpikir, cara kerja dan cara hidupnya, sehingga bersikap apatis terhadap adanya teknologi baru (Maryam et al., 2016).

Responden yang sudah mendapatkan pendidikan formal dan telah mengikuti berbagai pelatihan memiliki respon pengetahuan yang tinggi terhadap penyuluhan. Hal ini sependapat dengan penelitian Robiyanto et al. (2019) bahwa pendidikan mempengaruhi proses belajar, makin tinggi pendidikan seseorang makin mudah orang tersebut untuk menerima informasi baik dari orang lain maupun dari media.

Semakin lama beternak respon pengetahuan terhadap penyuluhan semakin tinggi. Diduga bahwa semakin lama usaha responden maka respon terhadap pengetahuan untuk menerima inovasi baru semakin meningkat. Berdasarkan penelitian Robiyanto et al. (2019), bahwa peternak responden yang mempunyai lama usaha tani 31-40 tahun mempunyai nilai yang cukup tinggi dengan kategori baik karena mempunyai pengalaman dan pengetahuan yang cukup dalam berternak. Jumlah ternak responden memiliki arah berbanding lurus dengan peningkatan pengetahuan, artinya semakin banyak ternak yang dimiliki maka peternak semakin respon terhadap penyuluhan, tetapi responnya sangat lemah yang dibuktikan dengan adanya peningkatan nilai yang fluktuatif. Hasil penelitian ini sependapat dengan penelitian Rahmah (2014) yang menyatakan bahwa skala usaha peternak sangat lemah terhadap tingkat respon pengetahuan, respon sikap dan partisipasi.

\section{Afektif (Sikap)}

Berdasarkan Tabel 3, seluruh responden setelah mendapatkan penyuluhan memiliki kategori sikap yang baik. Semakin bertambah umur maka responden semakin dewasa dalam bersikap dan bertindak untuk mengatasi permasalahan reproduksi ternak sapi potong. Faktor pendidikan peternak juga berbanding lurus terhadap respon sikap responden, artinya semakin tinggi pendidikan maka responden memiliki respon sikap yang lebih rasional dan motivasi kerja yang lebih tinggi. 
Tabel 3. Peningkatan sikap berdasarkan karakteristik responden

\begin{tabular}{lccc}
\hline Karakteristik Responden & Nilai Pre test & Nilai Postest & Selisih Nilai \\
\hline Umur peternak (tahun): & & & \\
$\quad$ 20-64 & 22,0 & 36,4 & 14,4 \\
$\quad$ > 64 & 23,0 & 38,0 & 15,0 \\
Pendidikan peternak: & & & \\
$\quad$ Formal & 21,6 & 35,5 & 13,9 \\
$\quad$ Formal dan Non formal & 23,5 & 39,6 & 16,1 \\
Lama Beternak (Tahun): & & & \\
1-10 & 22,0 & 35,3 & 13,3 \\
11-20 & 21,5 & 38,0 & 16,5 \\
$\quad$ 20 & 23,0 & 39,0 & 16,0 \\
Jumlah Ternak (ekor): & & & 12,0 \\
1-2 & 20,5 & 32,5 & 13,4 \\
3-4 & 21,8 & 35,2 & 16,2 \\
$\quad$-5 & 22,7 & 38,8 & \\
\hline
\end{tabular}

Sumber : Data primer diolah, 2021.

Semakin lama beternak, maka semakin tinggi pula respon sikapnya untuk menerapkan teknologi IB. Tetapi responden yang lama usahanya $>20$ tahun lebih rendah nilai peningkatan sikapnya dibandingkan responden yang lama usahanya 11-20 tahun, hal ini diduga dipengaruhi oleh kebiasaan lamanya dalam beternak. Menurut Maryam et al. (2016), bahwa kenyataan di lapangan sebagian besar peternak tidak melakukan perubahan-perubahan positif dalam meningkatkan usahanya berdasarkan pengalaman masing-masing, bahkan banyak peternak yang memiliki pengalaman yang memadai namun masih mengelola usaha yang sama dengan kebiasaan-kebisaan lama pada waktu mereka mengawali usahanya sampai sekarang.

Semakin banyak jumlah ternak yang dimiliki, respon sikap terhadap penyuluhan semakin tinggi. Artinya bahwa kepemilikan ternak lebih banyak memiliki motivasi yang tinggi untuk memperbaiki teknik reproduksi ternak dalam mengembangkan skala usahanya.

Hasil penelitian Kurnia, et al (2019), menjelaskan bahwa peternak dengan kepemilikan ternak yang banyak cenderung lebih terbuka terhadap penyuluhan karena mempengaruhi tingkat pendapatan dan berkembangnya skala usaha peternak tersebut.

\section{Efektivitas Penyuluhan \\ a. Analisis Peningkatan Pengetahuan}

Hasil uji normalitas berdasarkan one sample Kolmogorov-Smirnov, diketahui nilai signifikasi $0,200>0,05$, maka dapat disimpulkan bahwa nilai residual berdistribusi normal sehingga hasil analisis ini bisa lanjut ke analisis regresi. Pengaruh karakteritik reponden terhadap peningkatan pengetahuan berdasarkan hasil analisis regresi linier berganda dapat dilihat pada Tabel 4.

Tabel 4. Hasil analisis regresi linear berganda peningkatan pengetahuan

\begin{tabular}{lcc}
\hline \multicolumn{1}{c}{ Variabel } & Koefisien & Sig. \\
\hline Konstanta & -4.752 & \\
Umur peternak & 2.715 & 0.251 \\
Pendidikan peternak & 4.367 & 0.043 \\
Lama beternak & 2.222 & 0.043 \\
Jumlah ternak & 0.831 & 0.331 \\
\hline R Square $=0.602$ & & 0.000 \\
\hline
\end{tabular}

Sumber : Data primer diolah, 2021. 
Berdasarkan data pada Tabel 4, pengetahuan tentang reproduksi sapi meningkat $(\mathrm{P}<0,05)$ dipengaruhi oleh pendidikan dan lama beternak, dengan nilai signifikansi (Sig.) dalam uji $\mathrm{F}$ sebesar 0,000 . Oleh karena itu variable umur peternak, pendidikan peternak, lama beternak dan jumlah ternak secara simultan (bersama-sama) berpengaruh terhadap peningkatan pengetahuan.Tabel 5. Hasil analisis simple paired t-test peningkatan pengetahuan.

Selanjutnya nilai $R$ Squere adalah 0,602 atau sama dengan $60,2 \%$. Artinya bahwa variable $X$ secara simultan berpengaruh terhadap variabel Y sebesar $60,2 \%$. Sedangkan sisanya $39,8 \%$ dipengaruhi oleh variable lain di luar persamaan regresi ini atau variabel yang tidak diteliti. Hal ini disebabkan oleh terbatasnya variabel karakteristik responden yang dijadikan bahan penelitian.

Pengaruh yang signifikansi secara bersama-sama variabel karakteristik responden terhadap variabel peningkatan pengetahuan dapat dilihat dengan persamaan sebagai berikut: $\mathrm{Y}=-4.752+2.715 \mathrm{X} 1+4.367 \mathrm{X} 2+2.222 \mathrm{X} 3$ $+0.831 \mathrm{X} 4$

Berdasarkan persamaan tersebut, diketahui bahwa seluruh variabel $\mathrm{X}$ menunjukkan nilai koefisien korelasi positif, artinya semakin tinggi nilai variabel $X$ maka nilai variabel Y semakin meningkat.

Selanjutnya efektivitas penyuluhan dianalisis menggunakan uji-t, yaitu uji beda antara hasil pre test dan post test pengetahuan responden.

Hasil pengujian dapat dilihat pada Tabel 5 berikut:

Tabel 5. Hasil analisis simple paired t-test peningkatan pengetahuan

\begin{tabular}{llccc}
\hline Variabel & Rata-rata & N & Sebaran data & Std. Error \\
\hline Pre test & 23,20 & 30 & 3,210 & 0,586 \\
Post test & 35,30 & 30 & 5,086 & 0,929 \\
\hline
\end{tabular}

Corelation $=0,262$

Sig. $(2$ tailed $)=0,000$

Sumber : Data primer diolah, 2021.

Berdasarkan Tabel 5, nilai tes akhir lebih tinggi dari pada tes awal, tetapi rentang sebaran data tes akhir juga menjadi semakin lebar dengan standar error yang semakin tinggi. Selanjutnya nilai signifikansi $(\mathrm{P}<0,05)$, artinya hasil test awal dan test akhir terdapat perbedaan/peningkatan yang signifikan.

\section{b. Analisis Peningkatan Sikap}

Hasil uji normalitas berdasarkan one sample Kolmogorov-Smirnov, diketahui nilai signifikasi 0,200>0,05, artinya nilai residual berdistribusi normal. Pengaruh karakteritik reponden terhadap peningkatan sikap dapat dilihat pada Tabel 6 .

Tabel 6. Hasil analisis regresi linear berganda peningkatan sikap

\begin{tabular}{lcc}
\hline \multicolumn{1}{c}{ Variabel } & Koefisien & Sig. \\
\hline Konstanta & 9,481 & \\
Umur peternak & 0.407 & 0.782 \\
Pendidikan peternak & 0,623 & 0.633 \\
Lama beternak & 1.375 & 0.046 \\
Jumlah ternak & 0.460 & 0.391 \\
\hline R Square $=0.369$ & & 0.018 \\
\hline
\end{tabular}

Sumber : Data primer diolah, 2021.

Berdasarkan Tabel 6, respon sikap tanggap penyuluhan meningkat $(\mathrm{P}<0,05)$ dipengaruhi oleh lama beternak, dengan nilai signifikansi (Sig.) dalam uji $\mathrm{F}$ sebesar 0,018. 
Karena $\mathrm{P}<0,05$, maka variable umur peternak, pendidikan peternak, lama beternak dan jumlah ternak secara simultan berpengaruh terhadap peningkatan sikap.

Selanjutnya nilai $R$ Squere adalah 0,369 atau sama dengan $36,9 \%$. Artinya variable $X$ secara simultan berpengaruh terhadap variabel Y sebesar $36,9 \%$. Sedangkan sisanya $63,1 \%$ dipengaruhi oleh variable lain yang tidak diteliti. Diduga peningkatan sikap ini lebih besar dipengaruhi oleh faktor hubungan sosial antara penyuluh dengan peternak dalam berkelompok. Penyuluh lebih sering berkoordinasi dengan pengurus kelompok dibandingkan dengan anggota, baik melalui tatap muka perorangan maupun tatap muka kelompok, sehingga respon sikap peternak dalam menerima penyuluhan berbeda nyata.

Bulu (2016) menyatakan, bahwa sikap peternak terhadap suatu inovasi teknologi dipengaruhi oleh faktor internal individu (karakteristik kepribadian individu) dan faktor internal (faktor-faktor di luar diri individu). Akan tetapi yang lebih dominan mempengaruhi sikap dan keputusan peternak terhadap suatu inovasi adalah faktor-faktor eksternal, meliputi norma-norma, kebiasaan, komunikasi sosial,

interaksi sosial, dan belajar sosial individu peternak dalam sistem sosial.

Pengaruh yang signifikansi secara bersama-sama variabel karakteristik responden terhadap variabel peningkatan sikap dapat dilihat dengan persamaan sebagai berikut:

$\mathrm{Y}=9,481+0,407 \mathrm{X} 1+0,623 \mathrm{X} 2+1,375 \mathrm{X} 3+$

$$
0.460 \times 4
$$

Berdasarkan persamaan tersebut, seluruh variabel X menunjukkan nilai koefisien korelasi positif, artinya semakin tinggi nilai variabel $X$ maka nilai variabel $\mathrm{Y}$ semakin meningkat. Selanjutnya efektivitas penyuluhan dianalisis menggunakan uji-t, yaitu uji beda antara hasil pre test dan post test sikap responden.

Nilai tes akhir lebih tinggi dari pada tes awal, tetapi rentang sebaran data tes akhir juga menjadi semakin lebar dengan standar error yang semakin tinggi. Selanjutnya nilai signifikansi (2-tailed) adalah $0,000(\mathrm{P}<0,05)$, artinya hasil test awal dan test akhir terdapat perbedaan/peningkatan yang signifikan (Tabel 7). 7 berikut:

Hasil pengujian dapat dilihat pada Tabel

Tabel 7. Hasil analisis simple paired t-test peningkatan sikap

\begin{tabular}{lcccc}
\hline \multicolumn{1}{c}{ Variabel } & Rata-rata & N & Sebaran data & Std. Error \\
\hline Pre test & 22,10 & 30 & 2,295 & 0,419 \\
Post test & 36,60 & 30 & 3,318 & 0,606 \\
\hline
\end{tabular}

Corelation $=0,617$

Sig. $(2$ tailed $)=0,000$

Sumber : Data primer diolah, 2021.

\section{Service per Conception $(\mathrm{S} / \mathrm{C})$}

Service per Conception $(S / C)$

berdasarkan observasi lapang dapat dilihat pada

Table 4.8. Hasil penelitian menunjukkan adanya perbaikan S/C sapi potong pada peternak responden dari 3,3 (30\%) menjadi 2,2 (46\%), artinya keberhasilan IB meningkat $16 \%$.

Tabel 8. Service per Conception (S/C) sapi potong di Desa Japara

\begin{tabular}{lcc}
\hline \multicolumn{1}{c}{ Uraian } & Observasi I & Observasi II \\
\hline Jumlah sapi betina responden & 14 & 14 \\
Sapi betina yang di IB & 14 & 9 \\
Frekuensi IB (service) & 40 & 14 \\
Jumlah sapi bunting (Conception) & 12 & 6 \\
\hline S/C & 3,3 & 2,2 \\
\hline
\end{tabular}

Sumber : Data primer diolah, 2021. 
Data pada Tabel 8 menunjukan bahwa nilai service per conception $(S / C)$ sapi induk 2,2 artinya setiap perkawinan (IB) 2,2 kali menghasilkan 1 (satu) kebuntingan. Nilai S/C tersebut dianggap masih cukup tinggi, diduga disebabkan oleh deteksi birahi yang tidak akurat dan terlambat dalam melaksankan IB. Menurut Ananda et al. (2019), bahwa tingginya nilai S/C dapat disebabkan karena kelalaian peternak mendeteksi birahi dan terlambat melaporkan ternak yang estrus kepada inseminator. Serta pelaksanan IB yang tidak tepat waktu (Kusumawati et al., 2018).

Tingginya $\mathrm{S} / \mathrm{C}$ juga diduga dipengaruhi oleh manajemen pakan yang kurang baik sehingga berdampak terhadap reproduksi ternak, antara lain induk sapi tidak menunjukkan gejala estrus dalam jangka waktu yang lama (anestrus) pasca melahirkan (lebih dari 100 hari), sehingga berpengaruh terhadap fertilitas dan kejadian kebuntingan sapi terutama pada sapi yang dikawinkan secara IB. Anestrus atau penurunan aktivitas ovarium dihubungkan dengan penurunan kondisi tubuh, menimbulkan gagalnya siklus estrus karena ketidak cukupan nutrisi sebelum dan sesudah melahirkan (Achjadi, 2013).

\section{KESIMPULAN}

Berdasarkan hasil regresi linier, faktor pendidikan peternak dan lama beternak berpengaruh signifikan $(\mathrm{P}<0,05) \quad$ terhadap peningkatan pengetahuan responden, sementara peningkatan sikap responden hanya dipengaruhi oleh lama beternak $(\mathrm{P}<0,05)$. Berdasarkan hasil uji-t, dengan membandingkan antara hasil pretest dan posttest pada aspek pengetahuan dan sikap menunjukkan hasil yang signifikan, hal ini berarti terdapat perubahan atau peningkatan pengetahuan dan sikap responden. Berdasarkan hasil observasi lapang, adanya perbaikan S/C sebesar $16 \%$ pada sapi potong responden yang telah mendapatkan penyuluhan. secara umum pengetahuan dan sikap peternak terhadap aplikasi teknologi birahi dominan dipengaruhi oleh faktor pendidikan dan lama beternak, dan penyuluhan dinilai cukup efektif untuk meningkatkan penerapan teknologi tersebut.

\section{DAFTAR PUSTAKA}

ACHJADI, R. K. (2013). REPRODUKSI (Manajemen Reproduksi dan Penanganan Gangguan Reproduksi). Anggota Komisi Bibit Ditjen Peternakan dan Kesehatan Hewan Praktisi Kesehatan Reproduksi.
ADIYANTA, F. C. S. (2019). Hukum dan Studi Penelitian Empiris: Penggunaan Metode Survey sebagai Instrumen Penelitian Hukum Empiris. Administrative Law and Governance Journal, 2(4), 697-709. https://doi.org/10.14710/alj.v2i4.697-709

ANANDA et al. (2019). Hubungan Antara Umur dengan Calving Interval, Days Open, dan Service Per Conseption Sapi Friesian Holstein (FH). 8(2).

BADAN PUSAT STATISTIK. 2016. Populasi Ternak Menurut Kabupaten/ Kota dan Jenis Ternak di Provinsi Jawa Barat. Badan Pusat Statistik. Bandunga.

BULU, Y. G. (2016). Sikap Dan Perilaku Petani Terhadap Adopsi Teknologi Pertanian. Bptp, 1-9.

HIFIJAH. A., ASTATI., 2015. Analisis Faktor Keberhasilan Inseminasi Buatan Ternak Sapi Potong di Kecamatan Tombolo Pao Kabupaten Gowa. Jurnal Tekno sains. Volume 9 Nomor 1 Januari 2015 hlm. 13 - 26 Fakultas Sains dan Teknologi, Jurusan Ilmu Peternakan UIN Alauddin Makassar.

KUNINGAN MASS.2017. Program SIWAB (Sapi Induk Wajib Bunting) Kabupaten Kuningan. Diperoleh dari: https://kuninganmass.com/hore-prosespembuntingan-dimulai/] [Diakses 5/12/21].

KUSUMAWATI et al. (2018). Pengaruh Ketepatan Waktu Inseminasi Buatan Terhadap Tingkat Keberhasilan Kebuntingan Di Kecamatan Gedangan Kabupaten Malang Jawa Timur. Journal of Chemical Information and Modeling, 05(02), 1689-1699.

KURNIA et al. (2019). Pengaruh Umur, Pendidikan, Kepemilikan Ternak Dan Lama Beternak Terhadap Perilaku Pembuatan Mol Isi Rumen Sapi Di Kut Lembu Sura. 1(2), 40-49.

MARYAM et al. (2016). Analisis faktor-faktor yang mempengaruhi penentu pendapatan usaha peternakan sapi potong (studi kasus Desa Otting Kabupaten Bone). Jurnal Ilmu Dan Industri Peternakan, 3(1), 79-101.

MONA et al. (2015). Penggunaan Regresi Linear Berganda untuk Menganalisis Pendapatan Petani Kelapa. Studi Kasus: Petani Kelapa Di Desa Beo, Kecamatan Beo Kabupaten Talaud. D'CARTESIAN, 4(2), 196. 
https://doi.org/10.35799/dc.4.2.2015.921 1

MULYAWATI et al. (2016). Pengaruh Umur, Pendidikan, Pengalaman Dan Jumlah Ternak Peternak Kambing Terhadap Perilaku Sapta Usaha Beternak Kambing Di Desa Wonosari Kecamatan Patebon. Agromedia, 34(1), 85-90.

RAHMAH, U. I. L. (2014). Hubungan Antara Karakteristik Dengan Respon Peternak Terhadap Introduksi Teknologi Inseminasi Buatan ( IB ) Pada Ternak Domba ( Studi Kasus di Kecamatan Jatitujuh Kabupaten Majalengka ). Program Studi Peternakan, Fakultas Pertanian, Universitas Majalengka, 2(1996), 1-14.

ROBIYANTO et al. (2019). Peningkatan Pengetahuan Peternak Sapi Potong terhadap Teknologi Pengolahan Jerami Padi di Kabupaten Seluma Increased Knowledge of Beef Cattle Farmers on Rice straw Processing Technology in Seluma District. 978-979.

SUGIYONO. 2017. Metode Penelitian Kuantitatif, Kualitatif dan $R \& D$. CV. Alfabeta. Bandung.

SUHARJA, A.J. 2014. Persepsi Peternak Sapi Potong Terhadap Hasil Inseminasi Buatan (IB) Menggunakan Straw Simmental [Skripsi]. Program Studi Peternakan Fakultas Pertanian Universitas Majalengka.

YULIANDRI, LA., dkk. 2020. Hubungan Antara Karakteristik Peternak dan Inseminator Terhadap Tingkat Keberhasilan Inseminasi Buatan (IB) Dalam Program UPSUS SIWAB di Kabupaten Majalengka. Jurnal AGRIVET Volume 8 Nomor 1 Tahun 2020. 